\title{
Effect of a Nebulizer Holding Chamber on Aerosol Delivery
}

\author{
Rania M Sarhan MSc, Ahmed A Elberry PhD, Nada Saed Abdelwahab PhD, Hoda Rabea PhD, \\ Mohamed Nabil Salem PhD, and Mohamed EA Abdelrahim PhD
}

\begin{abstract}
BACKGROUND: A new holding chamber was designed to be used with the Aerogen Solo nebulizer to increase the aerosol emitted that reach the patient. The aim of this study was to evaluate the efficacy of this holding chamber with the nebulizer and determine its usability with other nebulizers. METHODS: The study was divided into 2 parts. In the first part, aerosol emitted of $1 \mathrm{~mL}$ respirable solution (nominal dose of $5000 \mu \mathrm{g}$ salbutamol), delivered by using the mesh nebulizer, Pro nebulizer, and jet nebulizer, connected to a T-piece or a holding chamber, was determined by using a breathing simulator set to provide a tidal volume of $500 \mathrm{~mL}$, frequency of $15 \mathrm{breaths} / \mathrm{min}$, and the inspiratory-expiratory ratio of 1:1 for adults as the quiet breathing pattern. Aerodynamic particle size characterizations were determined by using a cooled cascade impactor at an inhalation flow of $15 \mathrm{~L} / \mathrm{min}$. In the second part of the study, 12 healthy nonsmoking subjects ( 6 females) $>18 \mathrm{y}$, with an FEV1 $>90 \%$ were enrolled. Inhaled aerosol of $1 \mathrm{~mL}$ respirable solution $(5,000 \mu \mathrm{g}$ salbutamol) was delivered through the mesh nebulizer-holding chamber and an mesh nebulizer-T-piece using normal tidal breathing. The subjects provided urine samples 30 min after dosing and cumulatively collected their urine for $24 \mathrm{~h}$. The samples were analyzed for salbutamol content. RESULTS: The holding chamber significantly increased aerosol emitted by the 3 nebulizers compared with the T-piece $(P<.01)$ and relatively decreased the mass median aerodynamic diameter but with no significant difference. The mesh nebulizer-holding chamber resulted in significantly higher aerosol emitted compared with any other delivery method tested $(P<.01)$. The mesh nebulizer-holding chamber resulted in higher urine samples $30 \mathrm{~min}$ after dosing (as an index of lung deposition) and cumulatively collected urine for $24 \mathrm{~h}$ (as an index of systemic absorption) compared with the nebulizer-T-piece $(P<.05)$. CONCLUSIONS: The use of the holding chamber with a jet nebulizer, Pro nebulizer, and the Solo nebulizer significantly increased the aerosol delivery. The Solo nebulizer-holding chamber had the highest aerosol emitted compared with all nebulizer-adapter combinations and higher urine samples $\mathbf{3 0}$ min after dosing and cumulatively collected urine for $\mathbf{2 4} \mathrm{h}$ compared with the nebulizer-T-piece. Key words: jet nebulizer; nebulizer holding chamber; T-piece; Anderson cascade impactor; vibrating mesh nebulizer. [Respir Care 2018;63(9):1125-1131. () 2018 Daedalus Enterprises]
\end{abstract}

\section{Introduction}

At present, there are many types of nebulizers with different mechanisms and designs. ${ }^{1,2}$ Inhaled aerosols can be delivered to patients by using nebulizers with different adapters, for example, a T-piece, holding chamber, mouth-

Ms Sarhan, Dr Abdelrahim, and Dr Rabea are affiliated with the Clinical Pharmacy Department, Faculty of Pharmacy, Beni-suef University, Benisuef, Egypt. Dr Elberry is affiliated with the Clinical Pharmacology Department, Faculty of Medicine, Beni-suef University, Beni-suef, Egypt. Dr Abdelwahab is affiliated with the Analytical Chemistry Department, piece, or oronasal mask. ${ }^{3-5}$ A newly designed holding chamber for use with the Aerogen Solo vibrating mesh nebulizer (Aerogen, Galway, Ireland), is designed to improve effectiveness and decrease the loss due to exhalation and condensation. This Solo-holding chamber combination could result in much higher aerosol delivery to patients in

Faculty of Pharmacy, Beni-Suef University, Beni-Suef, Egypt. Dr Salem is affiliated with the Internal Medicine Department, Faculty of Medicine, Beni-suef University, Beni-suef, Egypt. Dr Abdelrahim is affiliated with the Clinical Pharmacy Department, Faculty of Pharmacy, Ahram Canadian University, Giza, Egypt. 
need of frequently administered nebulized medication. ${ }^{5,6}$ However, the high price of the Solo compared with jet nebulizers could be a barrier for some patients. This proposed beneficial effect of the holding chamber with the Solo, in addition to the cost issues, raises a question about the possibility of holding chamber use with a jet nebulizer or design of similar holding chambers for a jet nebulizer. The aim of the present study was to evaluate the efficacy of using the holding chamber and a T-piece with a jet nebulizer and the Aerogen Pro vibrating mesh nebulizer, and to compare their results with those of the Solo.

\section{Methods}

\section{Amount of Aerosol Emitted}

The nebulizers studied were the Solo, the Pro, and the Oxycare jet nebulizer (Ceren Uretim, Istanbul, Turkey) attached to a PortaNeb compressor (Philips Respironics, Murraysville, PA). The PortaNeb compressor provides an air flow of $6 \mathrm{~L} / \mathrm{min}$ into the jet nebulizer to aerosolize the liquid. The nebulizers were connected to either the standard nebulizer T-piece with a mouthpiece adapter or to the Aerogen Ultra as a holding chamber. The holding chamber adapter connections to the 3 different nebulizers studied are shown in Figure 1.

A lung simulator (model 5600i; Michigan Instruments, Grand Rapids, MI) was used to provide spontaneous breathing, with a tidal volume of $500 \mathrm{~mL}$, frequency of 15 breaths/min, and inspiratory-to-expiratory ratio of 1:1, which represent adults with a quiet breathing pattern, in accordance with the European Standard EN 13544-16 (CEN methodology). ${ }^{7}$ An electrostatic filter enclosed within a filter holder (Pari, Starnberg, Germany) was attached to the simulator from one side and the nebulizer-adapter combination from the other side, as shown in Figure 2. This filter traps all the aerosol produced during the inhalation period of a breathing cycle and thus provides a good measure of the in vitro emitted aerosol available for inhalation. ${ }^{8,9}$ The lung simulator was switched on $30 \mathrm{~s}$ before delivering the aerosol. The salbutamol respirable solution, $5,000 \mu \mathrm{g}$ in $1 \mathrm{~mL}$ (Farcolin respirator solution, $\mu \mathrm{g} / \mathrm{mL}$; Pharco Pharmaceuticals, Alexandria, Egypt), was nebulized to sputtering for the jet nebulizer and to dryness for the Solo and Pro nebulizers.

\section{The authors have disclosed no conflicts of interest.}

Correspondence: Mohamed E Abdelrahim PhD, Department of Clinical Pharmacy, Faculty of Pharmacy, Ahram Canadian University, Giza, Egypt, E-mail: mohamedemam9@yahoo.com

DOI: $10.4187 /$ respcare. 06061

\section{QUICK LOOK}

\section{Current knowledge}

Aerosol delivery by nebulizer results in a great loss of the drug into the surrounding, which results in less delivery to the patient. Holding chambers and holding chamber design can increase aerosol delivery.

\section{What this paper contributes to our knowledge}

The holding chamber with the jet nebulizer, Aerogen Pro vibrating mesh nebulizer, and Aerogen Solo vibrating mesh nebulizer increased the aerosol delivery more than with the T-piece. Aerogen Solo with the holding chamber had the highest delivery compared with all nebulizer-adapter combinations.

For each nebulizer-adapter combination, 5 determinations were made. The amounts of salbutamol deposited on the filter, left in the nebulizer reservoir chamber, and deposited inside the adapters used were recovered by rinsing with $20 \%$ acetonitrile. The amounts deposited on the filter were sonicated with $20 \%$ acetonitrile before rinsing. Highperformance liquid chromatography with ultraviolet detection was used to identify the amounts of salbutamol. This method used a $25 \mathrm{~mm} \times 4.6 \mathrm{~mm}$ ZORBAX Eclipse Plus C18, ODS1 column (Agilant, Santa Clara, CA) through which a mobile phase that consisted of a mixture of acetonitrile and water (which contained $0.1 \%$ phosphoric acid) (90:10, v/v), which was pumped at $1 \mathrm{~mL} / \mathrm{min}$ by using an Agilent 1260 Infinity preparative pump (G1361A). An Agilent 1260 Infinity Diode array detector VL (G131SD) was set at $225 \mathrm{~nm}$, with an injection volume of $100 \mu \mathrm{L}$. Calibration solutions ranged from 4 to $100 \mu \mathrm{g} / \mathrm{mL}$ (weight/volume). The limit of detection was $0.35 \mu \mathrm{g} / \mathrm{mL}$, and the lower limit of quantification was $2.55 \mu \mathrm{g} / \mathrm{mL}$.

\section{Particle Size Distribution of the Aerosol Emitted}

A cooled Anderson cascade impactor (Copley Scientific, Nottingham, United Kingdom) was used to determine the particle droplet size distribution of the aerosolized medication delivered. The Anderson cascade impactor, with its plates in situ, was placed in a refrigerator at $5{ }^{\circ} \mathrm{C}$ for $60 \mathrm{~min}$ before use. ${ }^{10}$ Immediately after removing the Anderson cascade impactor from the refrigerator, the inhalation flow was adjusted to $15 \mathrm{~L} / \mathrm{min}$ and the induction port of the Anderson cascade impactor was connected directly into the mouthpiece of the nebulizer-adapter combination and was tested, as shown in Figure 3. The vacuum 

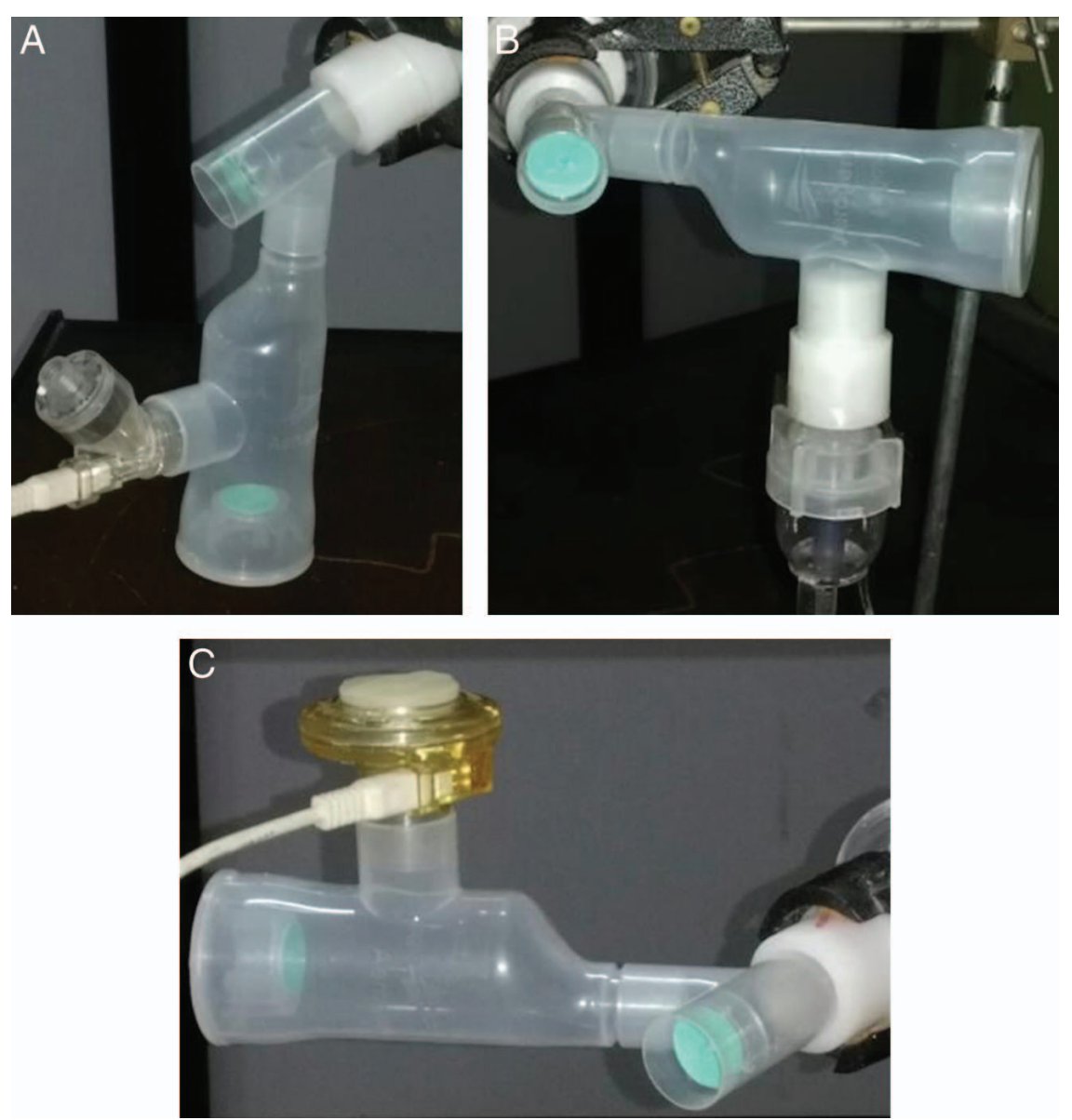

Fig. 1. The holding chamber connected to the Aerogen Solo vibrating mesh nebulizer (A), jet nebulizer (B), and Aerogen Pro vibrating mesh nebulizer (C).

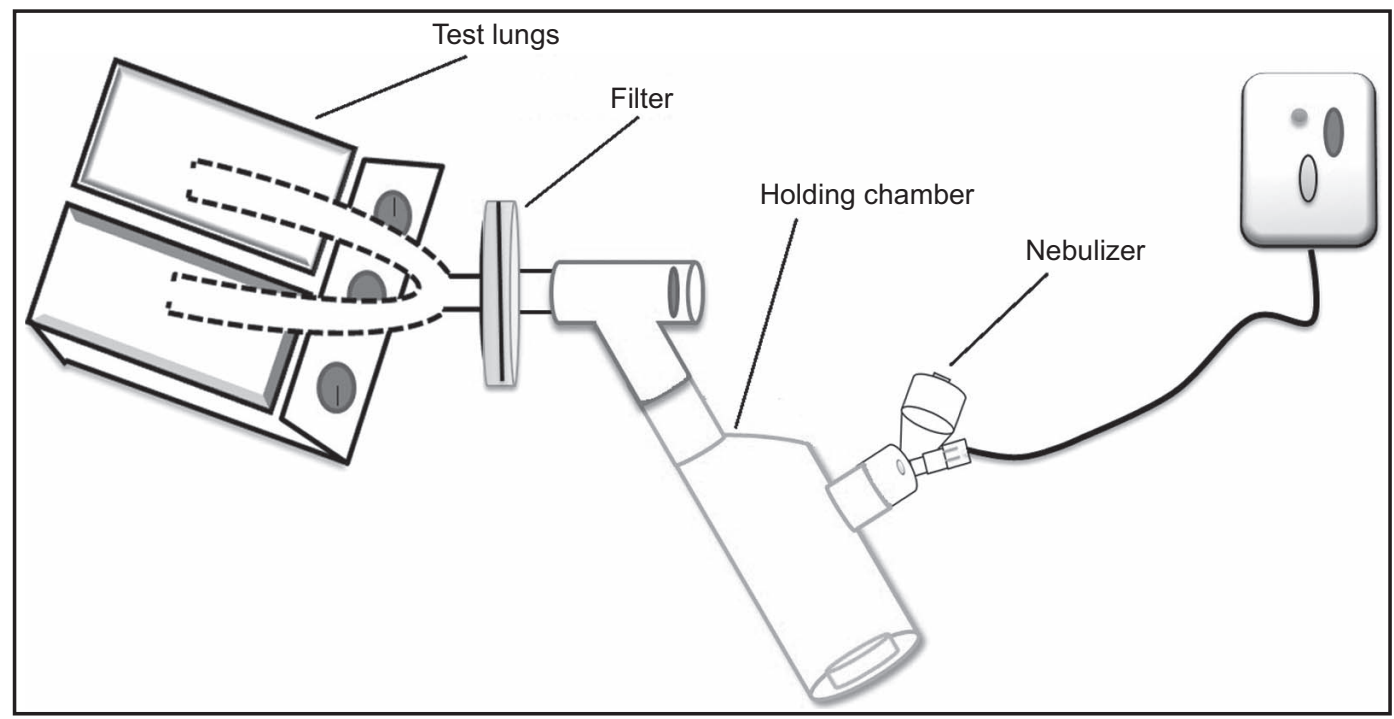

Fig. 2. Schematic diagram of the experimental setting for the determination of the amount of aerosol emitted. 


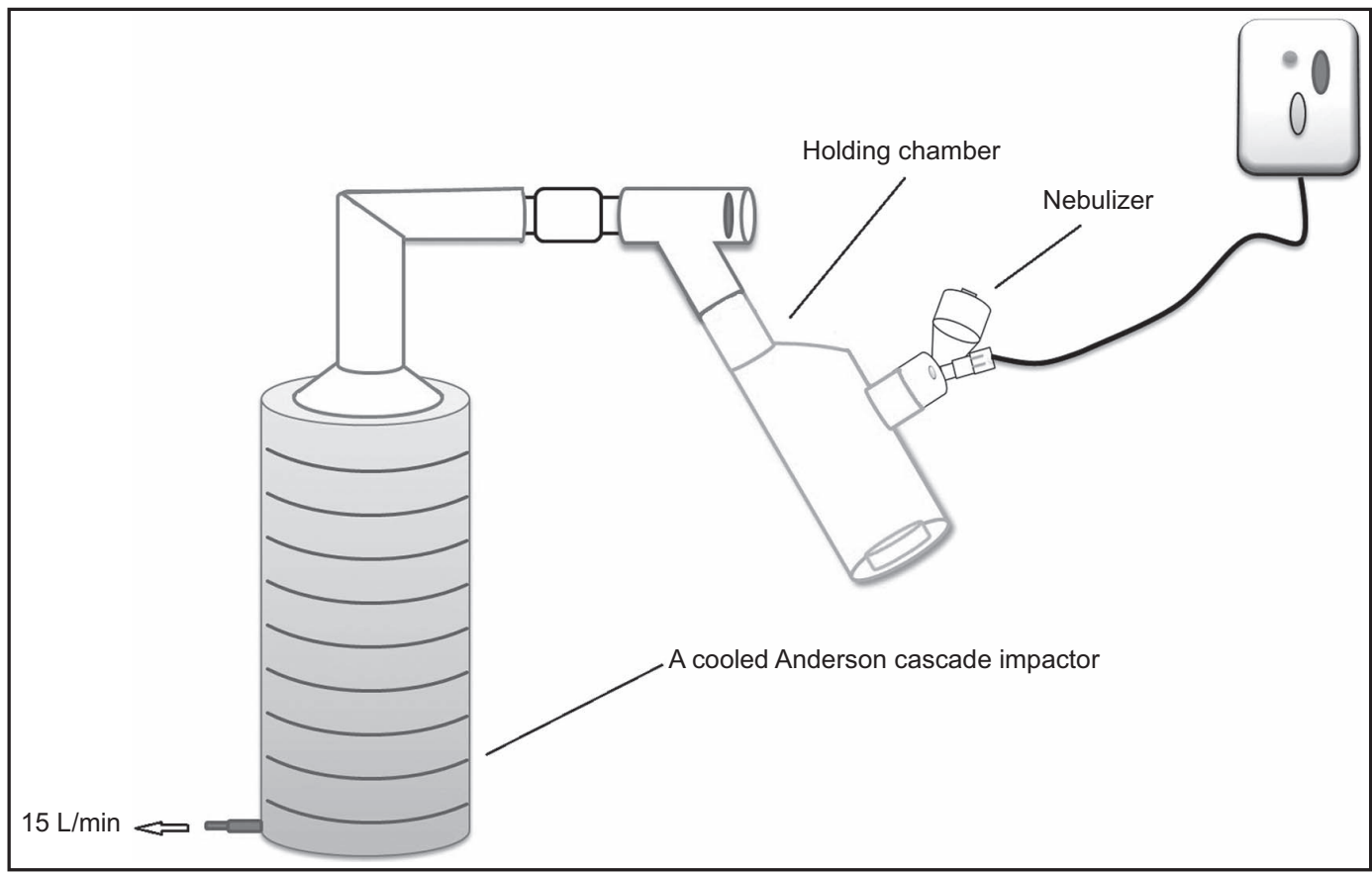

Fig. 3. Schematic diagram of the experimental setting for the determination of particle-size distribution of the aerosol emitted.

flow through the Anderson cascade impactor was provided by a Gast pump (Brook Crompton, Huddersfield, United Kingdom). The flow was measured by using an electronic digital flow meter (MKS Instruments, Andover, MA). The salbutamol respirable solution, $5,000 \mu \mathrm{g} / \mathrm{mL}$, was nebulized to sputtering for the jet nebulizer and to dryness for the Solo and Pro nebulizers. For each nebulizer adapter combination, 3 determinations were made.

Salbutamol deposited onto each plate of the Anderson cascade impacter, nebulizer reservoir chamber, and adapters was recovered by rinsing with $20 \%$ acetonitrile. Similarly, the mass entrained in the filter was recovered by sonication and rinsing. High-performance liquid chromatography was used as previously described. The fine-particle dose, fine-particle fraction, and the mass median aerodynamic diameter were determined by using Copley Inhaler Testing Data Analysis Software (CITDAS; Copley Scientific) impactor data.

\section{In Vivo Study}

Hindle and Chrystyn ${ }^{11}$ developed a urinary pharmacokinetic method to determine relative lung and systemic bioavailability of salbutamol after inhalation. ${ }^{11}$ This method used the amount of drug excreted in the first $30 \mathrm{~min}$ as an index of lung deposition and the amount of drug excreted over a 24-h period after inhalation as an index of the systemic absorption. ${ }^{11}$ This noninvasive pharmacokinetic method has been used to detect lung deposition of an aerosolized drug to healthy volunteers, ${ }^{12}$ subjects admitted with an exacerbation of either asthma or COPD, ${ }^{13}$ and subjects who were on ventilation. ${ }^{14-18}$ Similarly, we used this methodology to compare lung deposition and systemic absorption.

This study was conducted in accordance with the amended Declaration of Helsinki. Local institutional review boards and independent ethics committees approved the protocol, and written informed consent was obtained from all the subjects. Twelve non-smoking healthy subjects ( 6 females) $>18$ y with an FEV1 $>90 \%$ agreed to inhale a nebulized aerosol of salbutamol respiratory solution when using normal tidal breathing. They were first trained on how to inhale through the nebulizers. The subjects were trained to place the mouthpiece between their lips and breathe in and out gently through their mouth. Each subject randomly inhaled $1 \mathrm{~mL}$ of salbutamol respirable solution $(5,000 \mu \mathrm{g} / \mathrm{mL})$ from the holding chamber and the T-piece with the nebulizer that resulted in the greatest aerosol emitted in the in vitro part of the study. The dose was loaded into the nebulizer for the subject before use according to the patient information leaflet.

Both the volumes of the drug excreted in the first $30 \mathrm{~min}$ and the drug excreted over a 24-h period after inhalation were measured and then assayed by using high-performance liquid chromatography. Bambuterol hydrochloride was added as the internal standard to the collected urine samples. Salbutamol and bambuterol were extracted from the urine sample by using solid-phase extraction. ${ }^{16}$ The eluent was then injected into the highperformance liquid chromatography system, which was composed of an ODS $5 \mu \mathrm{m},(4.6 \times 250 \mathrm{~mm}$; ZORBAX 
Table 1. Results of Aerodynamic Characterization of $1 \mathrm{~mL}$ Respirable Solution (5,000 $\mu \mathrm{g}$ nominal dose) Delivered By Using Solo, Pro, and Jet Nebulizers With the T-Piece and Holding Chamber Adapter $(n=5)$

\begin{tabular}{|c|c|c|c|c|c|c|}
\hline & \multicolumn{2}{|c|}{ Jet Nebulizer } & \multicolumn{2}{|c|}{ Solo } & \multicolumn{2}{|c|}{ Pro } \\
\hline & $\begin{array}{c}\text { With } \\
\text { Holding Chamber }\end{array}$ & $\begin{array}{l}\text { With } \\
\text { T-Piece }\end{array}$ & $\begin{array}{c}\text { With } \\
\text { Holding Chamber }\end{array}$ & $\begin{array}{l}\text { With } \\
\text { T-Piece }\end{array}$ & $\begin{array}{c}\text { With } \\
\text { Holding Chamber }\end{array}$ & $\begin{array}{l}\text { With } \\
\text { T-Piece }\end{array}$ \\
\hline Aerosol emitted, mean $\pm \mathrm{SD} \mu \mathrm{g}$ & $956.7 \pm 155.1$ & $451.2 \pm 207.3$ & $2197.7 \pm 470.7$ & $1351.6 \pm 198.8$ & $1639.8 \pm 115.3$ & $1304.4 \pm 144.5$ \\
\hline Nebulizer residual, mean $\pm \mathrm{SD} \mu \mathrm{g}$ & $3467.1 \pm 300.3$ & $3387.0 \pm 216.5$ & $186.8 \pm 74.0$ & $261.1 \pm 98.0$ & $400.0 \pm 69.5$ & $448.4 \pm 93.0$ \\
\hline Connections, mean $\pm \mathrm{SD} \mu \mathrm{g}$ & $262.1 \pm 92.7$ & $210.3 \pm 70.7$ & $820.7 \pm 114.9$ & $603.2 \pm 76.5$ & $1385.7 \pm 257.1$ & $688.7 \pm 86.1$ \\
\hline Fine-particle fraction, mean $\pm \mathrm{SD} \%$ & $74.1 \pm 7.6$ & $67.6 \pm 5.6$ & $64.5 \pm 3.6$ & $67.9 \pm 1.7$ & $64.4 \pm 3.0$ & $49.9 \pm 4.0$ \\
\hline $\mathrm{MMAD}$, mean $\pm \mathrm{SD} \mu \mathrm{m}$ & $1.7 \pm 0.5$ & $2.1 \pm 1.1$ & $2.3 \pm 1.2$ & $2.9 \pm 0.5$ & $3.0 \pm 0.6$ & $3.8 \pm 0.4$ \\
\hline $\begin{array}{l}\text { Solo }=\text { Aerogen Solo vibrating mesh nebulizer } \\
\text { Pro }=\text { Aerogen Pro vibrating mesh nebulizer } \\
\text { Jet nebulizer }=\text { Oxycare jet nebulizer } \\
\text { MMAD = mass median aerodynamic diameter }\end{array}$ & & & & & & \\
\hline
\end{tabular}

Eclipse) C-18 high-performance liquid chromatography column with a $(4 \times 3 \mathrm{~mm}$, Agilent) $\mathrm{C}-18(\mathrm{ODS})$ guard column. The mobile phase, composed of acetonitrile water that contained $0.1 \%$ orthophosphoric acid (90:10, $\mathrm{v} / \mathrm{v})$, was pumped through the columns at a flow of $1 \mathrm{~mL} / \mathrm{min}$, maintained with a 25-photodiode-array detector set at $220 \mathrm{~nm}$. The lower detection limit and lower quantification limit for salbutamol were 0.36 and $1.00 \mu \mathrm{g} / \mathrm{mL}$, respectively. ${ }^{15}$

\section{Statistical Analysis}

All data are expressed as mean \pm SD. One-way analysis of variance with the application of least significant difference correction was used to compare the 6 different nebulizer adapter combinations. The urine samples were compared by using the Kruskal-Wallis analysis of variance, followed by the Mann-Whitney test for pairwise comparison by using SPSS V15.0 (SPSS, Chicago, Illinois).

\section{Results}

A summary of the in vitro results is provided in Table 1. The holding chamber significantly increased the emitted aerosol deposited onto the filter delivered by the 3 nebulizers compared with the T-piece $(P<.01)$. The 2 tested vibrating mesh nebulizers (Solo and Pro) used, had significantly higher aerosol emitted $(P<.001)$ and lower residual volume $(P<.001)$ compared with the jet nebulizer. The Solo-holding chamber resulted in a significantly higher aerosol emitted compared with any other nebulizer adapter combination tested $(P<.01)$. No significant difference was found between the amount deposited in the T-piece and the holding chamber when using the jet nebulizer. However, when using the Solo or Pro, the amount deposited inside the holding chamber was significantly higher than in the T-piece $(P<.05$ and $P<.001$, respectively).

The aerodynamic droplet-size distributions from the 6 different nebulizer-adapter combinations are shown in Table 1. The mass median aerodynamic diameter of the holding chamber with the 3 nebulizers was relatively lower compared with those with the T-piece, but no significant difference was found. The Pro-holding chamber resulted in significantly higher fine-particle fraction $(P<.001)$ compared with the Pro-T-piece. However no significant difference was found in the MMAD.

From the in vitro results, the Solo resulted in the highest aerosol emitted and so we chose it for the in vivo part of the study. Twelve subjects (6 females) with a mean \pm SD age, weight, and height of $33.3 \pm 5.6 \mathrm{y}, 82.7 \pm 7.4 \mathrm{~kg}$, and $168.0 \pm 4.9 \mathrm{~cm}$, respectively, completed the study. The $\mathrm{FEV}_{1}$ of all the subjects were $>90 \%$ of predicted value, with a mean $\pm \mathrm{SD}$ of $95.4 \pm 4.0 \%$ of the predicted value.

The mean \pm SD salbutamol excreted after inhalation from the Solo-holding chamber and Solo-T-piece during the $30 \mathrm{~min}$ after the start of the inhalation and cumulatively pooled for the next $24 \mathrm{~h}$ are presented in Table 2. The amount of drug excreted in the first $30 \mathrm{~min}$ and amount of drug excreted over a $24-\mathrm{h}$ period after inhalation from the Solo-holding chamber were significantly higher than from the Solo-T-piece $(P=.034$ and .02 , respectively).

\section{Discussion}

The performance of 20 disposable jet nebulizers had previously been evaluated to help the Aerosol Group of the French Cystic Fibrosis Society recommend a jet nebulizer for use in real life. ${ }^{19}$ However, any chosen jet nebulizer would deliver much lower aerosol emitted compared with vibrating mesh nebulizers..$^{8,10,20,21}$ We found 
Table 2. Salbutamol Excreted After Inhalation From Solo-Holding Chamber and Solo-T-Piece

\begin{tabular}{cccc}
\hline \hline & \multicolumn{2}{c}{ Solo } & \\
\cline { 2 - 3 } Salbutamol & $\begin{array}{c}\text { With Holding } \\
\text { Chamber }\end{array}$ & With T-piece & $P$ \\
\hline $\begin{array}{l}\text { Drug excreted }(30 \mathrm{~min}), \\
\text { mean } \pm \text { SD } \mu \mathrm{g}\end{array}$ & $110.1 \pm 82.7$ & $84.8 \pm 45.3$ & .034 \\
$\begin{array}{l}\text { Drug excreted }(24 \mathrm{~h}), \\
\text { mean } \pm \text { SD } \mu \mathrm{g}\end{array}$ & $906.1 \pm 572.6$ & $517.5 \pm 332.6$ & .02 \\
\begin{tabular}{l} 
Solo = Aerogen Solo vibrating mesh nebulizer \\
\hline
\end{tabular} & & \\
\hline
\end{tabular}

similar results in our study. The Solo and the Pro resulted in a much higher aerosol emitted than jet nebulizer $(P<.001)$.

Use of the holding chamber resulted in significantly higher amounts of delivered aerosol compared with the T-piece $(P<.01)$ with all the nebulizers studied. Hence, the holding chamber saved some of the exhaled aerosol when using the T-piece and decreased the fugitive aerosol. ${ }^{22}$ The holding chamber significantly increased $(P<.001)$ the aerosol emitted to double from the Solo. ${ }^{5}$ Also, the use of the holding chamber with a jet nebulizer significantly increased $(P<.01)$ the aerosol emitted to double that of the jet nebulizer-T-piece. These results extended the benefit of the tested holding chamber as an aerosol saver to the jet nebulizer. So, the patient who cannot afford the vibrating mesh nebulizers could use the present holding chamber or a similar holding chamber with the jet nebulizer for better delivery. Even though the aerosol emitted of jet nebulizer-holding chamber was 0.75 that of the Solo-T-piece, the use of the holding chamber with jet nebulizer would be beneficial in aerosol delivery compared with the T-piece or mouthpiece adapters. Furthermore, to increase the benefit of the holding chamber with a jet nebulizer, health-care providers would be asked to increase the fill volume by diluting the respirable dose placed in the jet nebulizer's nebulizer reservoir chamber, which was previously proven to increase the inhalable mass. ${ }^{22}$

The Pro-holding chamber also showed an increase in the aerosol emitted (1.25-fold) but not as much as when the holding chamber was used with the Solo or jet nebulizer. This might be due to the placement of the holding chamber below the Pro, as shown in Figure 1C. This setup could allow some condensation to occur on the walls of the holding chamber, with the help of aerosol inertial impaction and gravity, which would not occur with the Solo because the holding chamber and the Solo were placed side by side, as shown in Figure 1A. With the jet nebulizer, the position of the holding chamber was above the jet nebulizer, as shown in Figure 1B, so any condensation on the walls will return to the nebulizer reservoir chamber to be re-nebulized. ${ }^{8,9,23,24}$ The significant increases $(P<.001)$ of the amount left in the holding chamber compared with that in the T-piece with the Pro support this rationale and suggest that the 25\% increase in the aerosol emitted with the Pro-holding chamber was from the exhaled aerosol not the condensate. ${ }^{24}$

The Solo-holding chamber resulted in much better delivery than the Pro and the jet nebulizer or even the Solo itself with its T-piece. ${ }^{5,25}$ These results might have occurred because the holding chamber studied was designed for the Solo, with which it gives maximum advantage.

The uses of the holding chamber with the 3 nebulizers did not have much effect on the aerodynamic characterization. A relative insignificant decrease in the mass median aerodynamic diameter with the use of the holding chamber with all the nebulizers and a very slight increase in the fine-particle fraction were observed in the study. This was due to the nature of the nebulized aerosol, which does not contain propellant, like the metered-dose inhaler, which allows evaporation to take place when using a holding chamber or spacers. ${ }^{7,24}$ However, the main effect of the holding chamber is not to decrease the particle size of the aerosolized medication but to hold the nebulized aerosol from release to the surrounding area. ${ }^{26}$

The urinary data from the in vivo study showed similar results. The Solo-holding chamber significantly increased the amount of drug excreted over a 24-h period after inhalation by 1.8 -fold $(P=.02)$ and the amount of drug excreted in the first $30 \mathrm{~min}$ by 1.3 -fold $(P=.034)$ compared with the Solo-T-piece. Suggesting that the aerosol emitted determines the whole amount delivered to the patient but not the fraction deposited into the lungs. $., 27,28$

The holding chamber would deliver more medication to the patient, as presented here by the significant increase of the aerosol emitted, amount of drug excreted in the first $30 \mathrm{~min}$, and amount of drug excreted over a 24-h period after inhalation. These increases would be accompanied by a reduction of the aerosol lost to the atmosphere that may be inhaled by the health-care provider in the vicinity of the patient. 22,29 Hence, we recommend the use of the holding chamber with the jet nebulizer and the Pro for better aerosol delivery or the development of a holding chamber similar to that studied here for use with such nebulizers. Because the tested holding chamber with the Solo, the nebulizer designed to be used with the holding chamber had the greatest aerosol emitted $(P<.01)$. However, this should be done with caution, and a dose adjustment to avoid any possible adverse effects of the increase in systemic absorption.

\section{Conclusions}

The holding chamber did not have much effect on the mass median aerodynamic diameter and the fine-particle fraction. 


\section{Nebulizer Holding Chamber and Aerosol Delivery}

The use of a holding chamber with the jet nebulizer, Pro, and Solo significantly increased aerosol delivery compared with the T-piece. Therefore, the holding chamber could be of benefit when used with a jet nebulizer or Pro. It might be much better to develop a special holding chamber for the Pro and jet nebulizer, such as the holding chamber studied here because the Solo-holding chamber had the highest aerosol emitted compared with all nebulizer-adapter combinations and higher amount of drug excreted in the first $30 \mathrm{~min}$ and amount of drug excreted over a 24-h period after inhalation compared with the Solo-T-piece.

\section{REFERENCES}

1. Saeed H, Elberry AA, Eldin AS, Rabea H, Abdelrahim ME. Effect of nebulizer designs on aerosol delivery during non-invasive mechanical ventilation: a modeling study of in vitro data. Pulm Ther 2017;3(1):233-241.

2. Ari A. Jet, ultrasonic, and mesh nebulizers: an evaluation of nebulizers for better clinical outcomes. Eurasian J Pulmonol 2014;16:1-7.

3. Ari A, Restrepo RD. Aerosol delivery device selection for spontaneously breathing patients: 2012. Respir Care 2012;57(4):613-626.

4. Dolovich MB, Dhand R. Aerosol drug delivery: developments in device design and clinical use. Lancet 2011;377(9770):1032-1045.

5. Dunne RB, Shortt S. Comparison of bronchodilator administration with vibrating mesh nebulizer and standard jet nebulizer in the emergency department. Am J Emerg Med 2017; pii: S07356757(17)30907-5.

6. Lin HL, Cho HS, Wan GH, Hsieh MJ. Performance of different types of nebulizer with spontaneous adult breathing pattern. A50 asthma: observational studies. Am Thoracic Soc 2016;A1755.

7. Madney YM, Fathy M, Elberry AA, Rabea H, Abdelrahim ME. Nebulizers and spacers for aerosol delivery through adult nasal cannula at low oxygen flow rate: An in-vitro study. J Drug Deliv Sci Technol 2017;39:260-265.

8. Abdelrahim ME, Plant P, Chrystyn H. In-vitro characterisation of the nebulised dose during non-invasive ventilation. J Pharm Pharmacol 2010;62(8):966-972.

9. Hassan A, Rabea H, Hussein RR, Salah Eldin R, Abdelrahman MM, Said ASA, et al. In-vitro characterization of the aerosolized dose during non-invasive automatic continuous positive airway pressure ventilation. Pulm Ther 2016;2(1):115-126.

10. Abdelrahim ME. Aerodynamic characteristics of nebulized terbutaline sulphate using the Andersen Cascade Impactor compared to the Next Generation Impactor. Pharm Dev Technol 2011;16(2):137-145.

11. Hindle M, Chrystyn H. Determination of the relative bioavailability of salbutamol to the lung following inhalation. Br J Clin Pharmacol 1992;34(4):311-315.

12. Silkstone VL, Dennis JH, Pieron CA, Chrystyn H. An investigation of in vitro/in vivo correlations for salbutamol nebulized by eight systems. J Aerosol Med 2002;15(3):251-259.

13. Mazhar SH, Ismail NE, Newton DA, Chrystyn H. Relative lung deposition of salbutamol following inhalation from a spacer and a Sidestream jet nebulizer following an acute exacerbation. Br J Clin Pharmacol 2008;65(3):334-337.

14. Hassan A, Salah Eldin R, Abdelrahman MM, Abdelrahim ME. Invitro/in-vivo comparison of inhaled salbutamol dose delivered by jet nebulizer, vibrating mesh nebulizer and metered dose inhaler with spacer during non-invasive ventilation. Exp Lung Res 2017;43(1):19-28.

15. Rabea H, Ali AM, Salah Eldin R, Abdelrahman MM, Said AS, Abdelrahim ME. Modelling of in-vitro and in-vivo performance of aerosol emitted from different vibrating mesh nebulisers in noninvasive ventilation circuit. Eur J Pharm Sci 2017;97:182-191.

16. ElHansy MHE, Boules ME, El Essawy AFM, Al-Kholy MB, Abdelrahman MM, Said ASA, et al. Inhaled salbutamol dose delivered by jet nebulizer, vibrating mesh nebulizer and metered dose inhaler with spacer during invasive mechanical ventilation. Pulm Pharmacol Ther 2017;45:159-163.

17. Moustafa IOF, Ali MRA, Al Hallag M, Rabea H, Fink JB, Dailey P, Abdelrahim MEA. Lung deposition and systemic bioavailability of different aerosol devices with and without humidification in mechanically ventilated patients. Heart Lung 2017;46(6):464-467.

18. Hussein RRS, M A Ali A, Salem HF, Abdelrahman MM, Said ASA, Abdelrahim MEA. In vitro/in vivo correlation and modeling of emitted dose and lung deposition of inhaled salbutamol from metered dose inhalers with different types of spacers in noninvasively ventilated patients. Pharm Dev Technol 2017;22(7):871-880.

19. Vecellio L, Abdelrahim ME, Montharu J, Galle J, Diot P, Dubus JC. Disposable versus reusable jet nebulizers for cystic fibrosis treatment with tobramycin. J Cyst Fibros 2011;10(2):86-92.

20. Abdelrahim ME, Plant PK, Chrystyn H. The relative lung and systemic bioavailability of terbutaline following nebulisation in noninvasively ventilated patients. Int J Pharm 2011;420(2):313-318.

21. Abdelrahim ME, Chrystyn H. Aerodynamic characteristics of nebulized terbutaline sulphate using the Next Generation Impactor (NGI) and CEN method. J Aerosol Med Pulm Drug Deliv 2009;22(1):19-28.

22. Saeed H, Mohsen M, Fink JB, Dailey P, Salah Eldin A, Abdelrahman MM, et al. Fill volume, humidification and heat effects on aerosol delivery and fugitive emissions during noninvasive ventilation. J Drug Deliv Sci Technol 2017;39:372-378.

23. ElHansy MHE, Boules ME, Farid H, Chrystyn H, El-Maraghi SK, Al-Kholy MB, et al. In vitro aerodynamic characteristics of aerosol delivered from different inhalation methods in mechanical ventilation. Pharm Dev Technol 2017;22(6):844-849.

24. Harb HS, Elberry AA, Rabea H, Fathy M, Abdelrahim ME. Is Combihaler usable for aerosol delivery in single limb non-invasive mechanical ventilation? J Drug Deliv Sci Technol 2017;40:28-34.

25. Loborec SM, Johnson SE, Keating EA. Financial effect of converting ipratropium-albuterol therapy from inhalers to nebulizer treatments at an academic health system. Am J Health Syst Pharm 2016; 73(3):121-125.

26. Dugernier J, Hesse M, Vanbever R, Depoortere V, Roeseler J, Michotte JB, et al. SPECT-CT comparison of lung deposition using a system combining a vibrating-mesh nebulizer with a valved holding chamber and a conventional jet nebulizer: A randomized cross-over study. Pharm Res 2017;34(2):290-300.

27. Schloss J, Mitchell JP. Evaluating upper and lower airway nebulizer-delivery of an inhaled reliever medication for bronchoconstrictive disease in the laboratory, simulating adult tidal breathing and using an anatomic oropharyngeal model. Respir Care 2016; 61(10).

28. Dunne R, Shortt S, Dailey P. 135 Aerosol dose matters in the emergency department: A comparison of the impact of bronchodilator administration with two nebulizer systems. Ann Emerg Med 2016;68(4):S54.

29. Ari A, Fink JB, Pilbeam SP. Secondhand aerosol exposure during mechanical ventilation with and without expiratory filters: An invitro study. Indian J Respir Care 2016;5(1):1-6. 